\title{
HEMODYNAMIC EFFECTS OF ACUTE AND PROLONGED $\beta$-ADRENERGIC BLOCKADE IN ESSENTIAL HYPERTENSION
}

\author{
Lennart Hansson, ${ }^{1}$ Andrew J. Zweifler, Stevo Julius and Stephen N. Hunyor \\ From the Department of Internal Medicine, Hypertension Section, University of Michigan Medical Center,
} Ann Arbor, Michigan, USA

\begin{abstract}
Hemodynamic studies have been performed in 15 male patients with mild to moderately severe essential hypertension. Studies were made after four weeks of placebo treatment and again after acute i.v. administration of propranolol $(0.22 \mathrm{mg} / \mathrm{kg})$ and after four weeks of oral propranolol therapy (160-320 mg daily). After acute $\beta$-adrenergic blockade a significant reduction of cardiac index (Qi) occurred, while total peripheral resistance (TPR) increased significantly, resulting in unaltered BP. After four weeks of oral propranolol the Qi remained significantly reduced, but TPR was readjusted towards the initial level, resulting in a reduction of $\mathrm{BP}$ in most patients. Major reductions of stimulated plasma renin activity were seen, but these were not correlated to the changes of BP, Qi or TPR. Studies of the baroreceptor reflex by means of i.v. administration of angiotensin suggested a change towards increased sensitivity, although this change did not achieve statistical significance.
\end{abstract}

Antihypertensive effect of propranolol has been reported in several studies $(6,8,14,15,20,23)$. As most forms of established hypertension are characterized by increased total peripheral vascular resistance (TPR) and normal cardiac output (Q) $(5,11,17)$, the antihypertensive properties of propranolol have been hard to explain in view of its predominantly cardiac effects. Several suggestions have been offered as tentative explanations, e.g. resetting of baroreceptors (15), central nervous effects (6), adaptation of vascular resistance in response to chronic reduction of $Q(20)$ and local anesthetic effects on vasoconstrictor fibers (4). Lately, propranolol-induced reduction of plasma renin activity (PRA) in hypertensive patients

1 Present address: Department of Internal Medicine I, Sahlgren's Hospital, University of Göteborg, Göteborg, Sweden. has been demonstrated $(2,9)$, which may be of importance in the hypotensive mechanism, especially in conditions with high plasma renin. As the effects of acute and chronic administration of propranolol are different, particularly in regard to the effect on $\mathrm{BP}(16,20,21)$, further confusion has resulted.

For this reason the present study was designed with the intention of studying the antihypertensive effect of propranolol, particularly the hemodynamic alterations resulting from acute and chronic $\beta$-adrenergic blockade. We were interested to see whether TPR would readjust in the presence of continuously reduced $Q$. In addition, special interest was directed to the study of baroreceptor sensitivity and whether a change would take place. Finally, PRA was studied with the intention of exploring connections between changes of renin and changes of peripheral vascular resistance.

\section{MATERIAL AND METHODS}

Fifteen male patients with mild to moderate essential hypertension were studied. Their average age was 44 years (range 26-66). The average known duration of hypertension was 6.5 years (range $0-17$ ). Before entering the study all patients but two were receiving antihypertensive therapy, usually consisting of $\alpha$-methyldopa and/or diuretics.

Secondary causes of hypertension were excluded in all patients by a thorough clinical examination, rapid sequence i.v. pyelograms and laboratory studies (serum electrolytes, PRA and urinary excretion of aldosterone, epinephrine and norepinephrine). In addition ECG, chest X-ray, urine microscopy, serum creatinine, serum lipids and liver function were checked repeatedly during the study.

All patients were told of the investigational nature of the study and gave their informed consent to participation in it. 


\section{Plan of study}

After stopping all previous therapy, the patients were given placebo treatment in a single blind fashion on an outpatient basis. Placebo treatment continued for four weeks, after which the patients were hospitalized for baseline studies, including the first hemodynamic study. They were discharged after four days and were put on oral propranolol, $40 \mathrm{mg}$ four times daily, as the sole antihypertensive treatment. After two weeks this dosage was increased to $80 \mathrm{mg}$ four times daily unless a diastolic BP reduction of $15 \mathrm{mmHg}$ or more was observed. Treatment with propranolol was continued for another two-week period. The average daily propranolol dosage during weeks 3 and 4 was $250 \mathrm{mg}$. After four weeks of oral propranolol treatment a repeated hemodynamic study was performed.

\section{Hemodynamic methods}

The hemodynamic studies were performed in the morning with the patients fasting.

Systemic arterial pressure was measured in the brachial artery by a Statham strain gauge receptor (P 23 G). Mean arterial pressure (MAP) was calculated as the diastolic $\mathrm{BP}+1 / 3$ of the pulse pressure.

$\mathrm{Q}$ was determined by the indicator dilution technique (12) using a Gilford densitometer and Indocyanine green (Cardio-Green).

Respiratory movements were monitored continuously by means of a bellows attached around the chest and connected to a strain gauge by a rubber tube. The standard leads of the ECG were connected and lead I was recorded continuously on a Gilson polygraph together with intraarterial BP, respiration and dye curves.

Stroke volume (SV) was calculated by dividing $Q$ by heart rate (HR). TPR was obtained by dividing MAP by $Q$ and was expressed in arbitrary units (U). Q, TPR and SV were corrected for body surface area and the corresponding indices Qi, TPRi and SVi were derived.

PRA was measured with a radioimmunoassay technique (7) in the initial untreated state during tilt (stimulated), and again in the tilted position after acute and prolonged $\beta$-adrenergic blockade.

\section{Hemodynamic study I}

The first resting $Q$ was determined $15 \mathrm{~min}$ after all catheters were placed. The patients were then tilted to a $45^{\circ}$ head-up position for $10 \mathrm{~min}$ and $\mathrm{Q}$ and PRA were determined. Approximately $10 \mathrm{~min}$ after resumption and under resting conditions the baroreceptor reflex was assessed. This was done by rapid i.v. administration of angiotensin (Hypertensin Ciba), usually $1.5 \mu \mathrm{g}$, while recording changes in BP and HR. Systolic BP was plotted against the corresponding $R-R$ interval in the ECG, using the technique of Bristow et al. (1). Plotting was continued until the pressure peak occurred. No data during inspiration were used. Usually $15-30$ points could be plotted in this way for each patient. The points were then analysed with a standard correlation test and only if a statistically significant correlation resulted $(p<0.05)$ was the BP/R-R slope used for further comparisons.
Propranolol was then administered intravenously, $0.05 \mathrm{mg} / \mathrm{kg}$ b.wt. over $2 \mathrm{~min}$. Q was determined $8 \mathrm{~min}$ after the completion of the injection. An additional amount of propranolol, $0.05 \mathrm{mg} / \mathrm{kg}$, was then given and $\mathrm{Q}$ measurements were repeated after an identical interval. Finally, a third injection of $0.12 \mathrm{mg}$ propranolol $/ \mathrm{kg}$ was given, bringing the total dosage to $0.22 \mathrm{mg} / \mathrm{kg}$. Hemodynamic determinations were then repeated. The $10-\min 45^{\circ}$ head-up tilt was then repeated, at the end of which hemodynamics were determined.

\section{Hemodynamic study II}

The second hemodynamic study was done at the same time of day and under identical conditions as the first study, but following four weeks of oral propranolol treatment. The same studies were repeated with the exception that i.v. propranolol was not given and only one 10 -min period of tilt with Q and PRA measurements was performed.

Statistically significant BP/R-R slopes were obtained at both the first and second hemodynamic study in 7 patients. Only data from these 7 patients were used for comparisons (paired $t$-test).

\section{Assessment of $\beta$-adrenergic blockade}

The degree of $\beta$-adrenergic blockade was tested three times during the study by continuous i.v. infusion of a $\beta$-adrenergic stimulant-isoproterenol-while monitoring HR on the ECG. On each occasion HR was determined before the start of the infusion. Isoproterenol was then given in a constant i.v. infusion of $3 \mu \mathrm{g} / \mathrm{ml}$ at the rate of $1 \mathrm{ml} / \mathrm{min}$ for $3 \mathrm{~min}$. The response to $\beta$-adrenergic stimulation was taken as the difference between the final HR and the HR before the start of the infusion.

The first assessment of response to isoproterenol was made after four weeks of oral placebo treatment before any propranolol had been given. The second determination was made after i.v. administration of $0.22 \mathrm{mg}$ propranolol $/ \mathrm{kg}$, and the final assessment after four weeks of oral propranolol therapy and approximately 2 hours after the last dose.

\section{Plasma propranolol determinations}

Plasma propranolol concentration was determined by fluorimetric technique (18) by Ayerst Laboratories, Montreal, Canada. Blood samples were drawn $20 \mathrm{~min}$ after the completion of the i.v. injection of propranolol and again, following four weeks of oral treatment, approximately $90 \mathrm{~min}$ after the last dose. The plasma was separated by centrifugation and chilled to $4^{\circ} \mathrm{C}$ before being sent in an isolated tube for analysis.

\section{Statistical methods}

Student's $t$-test, the $t$-test for paired observations and correlation coefficients were calculated using the Midas (Constat) computer program of the Statistical Research Laboratory at the University of Michigan. 


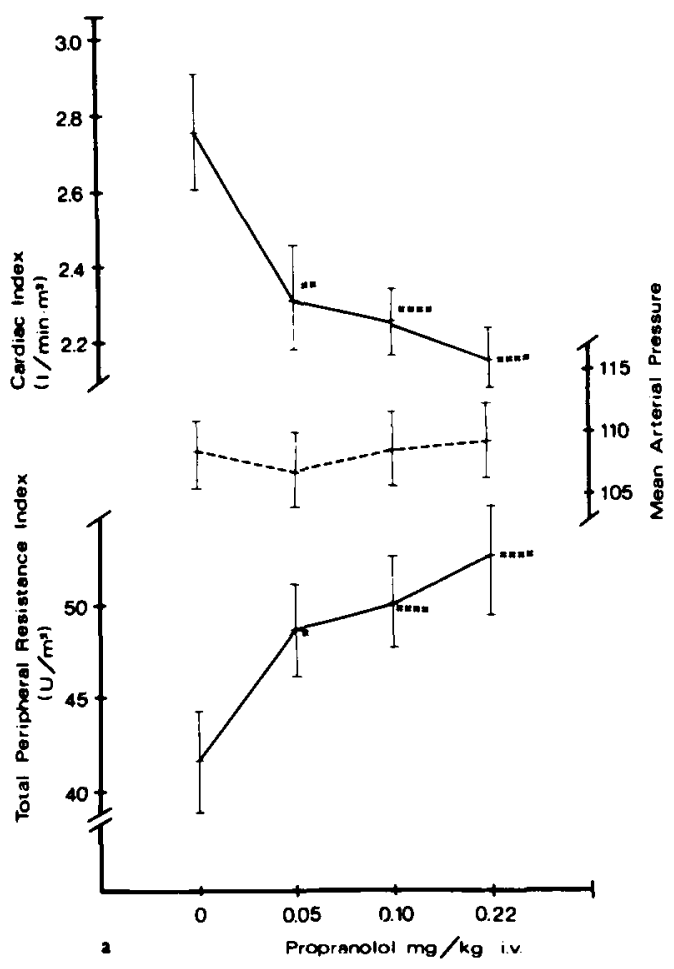

Fig. $l a$ and $b$. Effect of increasing doses of i.v. propranolol (mean \pm S.E.M.). The cumulated doses on the $x$-axis were given with 10 -min intervals. Statistical

\section{RESULTS}

\section{Effect of intravenous propranolol}

As illustrated in Fig. $1 a$, even $0.05 \mathrm{mg} / \mathrm{kg}$ of i.v. propranolol caused a marked drop of Qi from 2.76 to $2.29 \mathrm{l} / \mathrm{min} \cdot \mathrm{m}^{2}(p<0.01)$. TPRi increased from 41.3 to $48.5 \mathrm{U} / \mathrm{m}^{2}(p<0.05)$, thereby minimizing the effect on MAP which remained virtually unchanged (108.3 vs. $107.2 \mathrm{mmHg}, p>0.25$ ).

Further administration of propranolol, to a total dosage of 0.10 and $0.22 \mathrm{mg} / \mathrm{kg}$, respectively, caused further non-significant reductions of $\mathrm{Qi}$

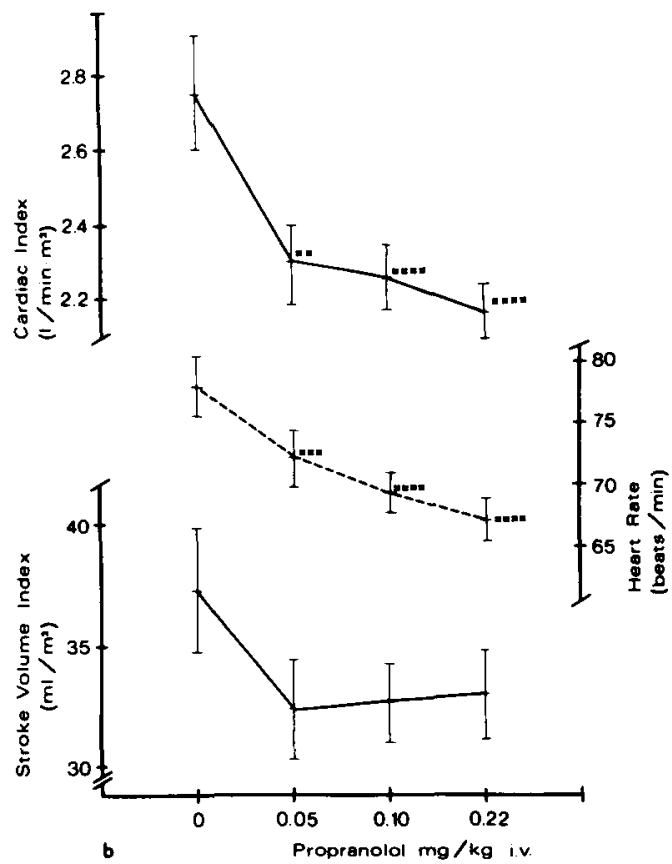

comparison (paired $t$-test) is with initial values.

${ }^{\times} p<0.05,{ }^{x \times} p<0.01,{ }^{x \times x} p<0.005,{ }^{x \times x \times} p<0.001$.

and increments of TPRi, while MAP remained unchanged (Fig. $1 a$ ). The overall hemodynamic effects are given in Table I. As illustrated in Fig. $1 b$, the reduction of Qi was mainly the effect of decreased HR, while SVi did not change significantly.

\section{Effect of four weeks of oral propranolol therapy}

The effect of four weeks of oral propranolol therapy was similar to the acute effects of i.v. propranolol in that Qi remained at a significantly lower level than initially, albeit the reduction was

Table I. Hemodynamic changes at rest

\begin{tabular}{|c|c|c|c|c|c|c|c|}
\hline & \multirow[b]{2}{*}{ Placebo } & \multicolumn{6}{|c|}{ Propranolol } \\
\hline & & I.v. ${ }^{a}$ & Difference $^{c}$ & $p<$ & Orally & Difference $^{c}$ & $p<$ \\
\hline $\begin{array}{l}\text { Qi }\left(1 / \mathrm{min} \cdot \mathrm{m}^{2}\right) \\
\text { MAP }(\mathrm{mmHg}) \\
\text { TPRi }\left(\mathrm{U} / \mathrm{m}^{2}\right) \\
\text { HR }(\text { beats } / \mathrm{min}) \\
\text { SVi }\left(\mathrm{ml} / \mathrm{m}^{2}\right)\end{array}$ & $\begin{array}{c}2.76 \\
108.3 \\
41.3 \\
76.0 \\
37.3\end{array}$ & $\begin{array}{c}2.18 \\
109.9 \\
52.3 \\
67.1 \\
33.0\end{array}$ & $\begin{array}{c}0.58 \\
1,7 \\
11.0 \\
8.9 \\
4.3\end{array}$ & $\begin{array}{l}0.001 \\
\text { n.s. } \\
0.005 \\
0.0001 \\
\text { n.s. }\end{array}$ & $\begin{array}{c}2.35 \\
102.1 \\
43.9 \\
59.6 \\
40.2\end{array}$ & $\begin{array}{c}0.41 \\
6.2 \\
2.6 \\
16.4 \\
2.9\end{array}$ & $\begin{array}{l}0.01 \\
0.05 \\
\text { n.s. } \\
0.0001 \\
\text { n.s. }\end{array}$ \\
\hline
\end{tabular}

$0.22 \mathrm{mg} / \mathrm{kg}$. ${ }^{b}$ For 4 weeks, $160-320 \mathrm{mg} /$ day. ${ }^{c}$ Compared to measurement after placebo. 

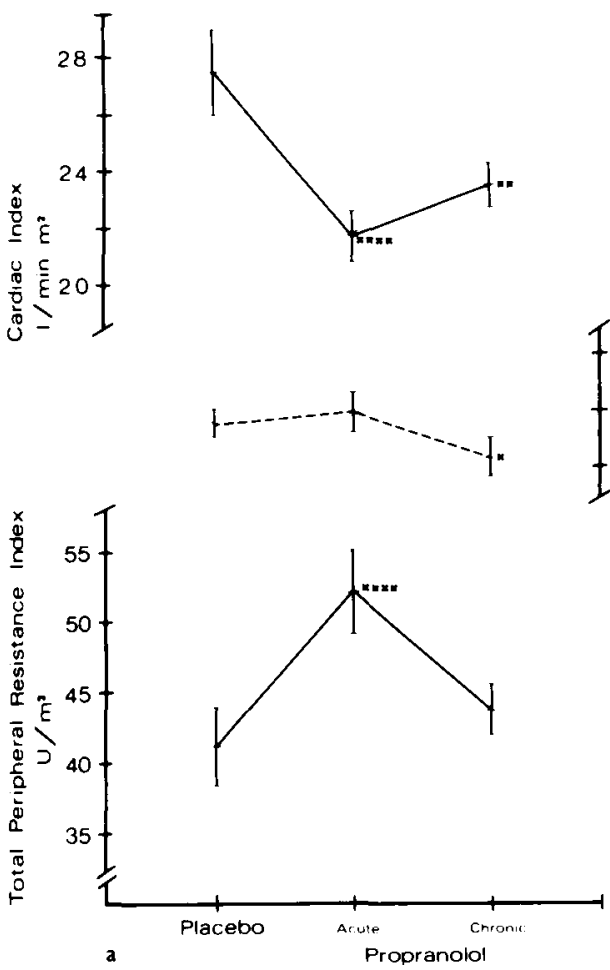

Fig. $2 a$ and $b$. Effects of acute i.v. and chronic oral administration of propranolol (mean \pm S.E.M.). Statistics as in Fig. 1.

not as pronounced (Table I, Fig. 2a). The reduction of Qi was mainly an effect of reduced HR, whereas SVi did not change significantly (Fig. $2 b$ ).

However, in contrast to the effect of acute $\beta$ adrenergic blockade there now was a reduction of MAP (Fig. 2a). TPRi was correspondingly less elevated than after acute propranolol and as a matter of fact was not significantly higher than in the untreated state.

Analysis of the hemodynamic changes in inidvidual patients revealed that, while 12 patients showed reduced MAP after four weeks of propranolol therapy, 3 showed no decrease or even an increased MAP. For this reason the 12 "responders" were compared to the 3 "nonresponders".

Already after acute i.v. propranolol there was a significant difference in MAP between the two groups (MAP 105.9 vs. $121.4 \mathrm{mmHg}, p<0.05$ ) (Fig. 3). As expected, this difference was even more pronounced after four weeks of oral propranolol (MAP 97.1 vs. $122.2 \mathrm{mmHg}, p<0.001$ ). There were no significant differences between responders and non-responders regarding Qi, but
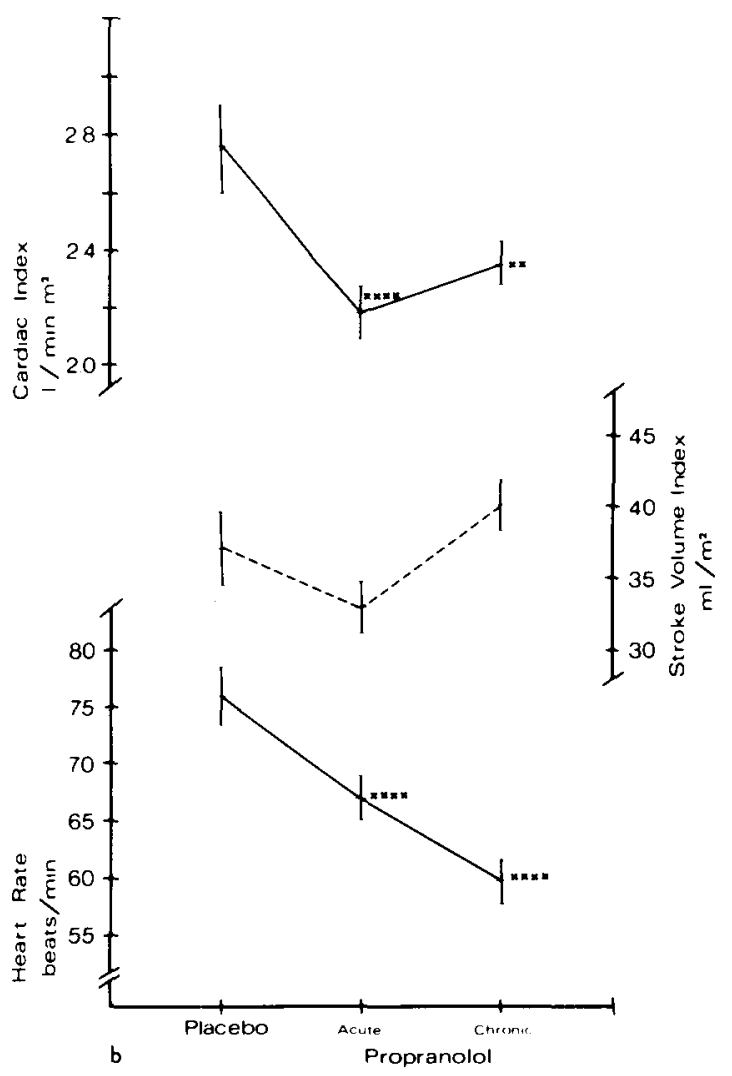

after four weeks of oral propranolol responders had significantly lower TPRi (42.3 vs. $50.2 \mathrm{U}$; $p<0.05$ ) (Fig. 3). Differences in HR and SVi were insignificant both after acute and chronic $\beta$ adrenergic blockade.

\section{Effects of tilt}

The hemodynamic effects of tilt in the untreated state, after acute i.v. propranolol and after 4 weeks of oral therapy, are presented in Table II. Propranolol blocked the HR response to tilt both after acute and chronic administration. The well known reduction of $\mathrm{Q}$ during tilt was observed also after acute, and to a lesser extent after chronic, $\beta$-adrenergic blockade. Finally, the chronic $\beta$-adrenergic blockade did not interfere with the homeostasis of BP during tilt. Significant increases of MAP were seen in this situation both after placebo and after 4 weeks of oral propranolol. On the other hand a non-significant reduction of MAP occurred after acute i.v. propranolol.

\section{Effect on plasma renin activity}

PRA after tilt in the untreated state, after acute 


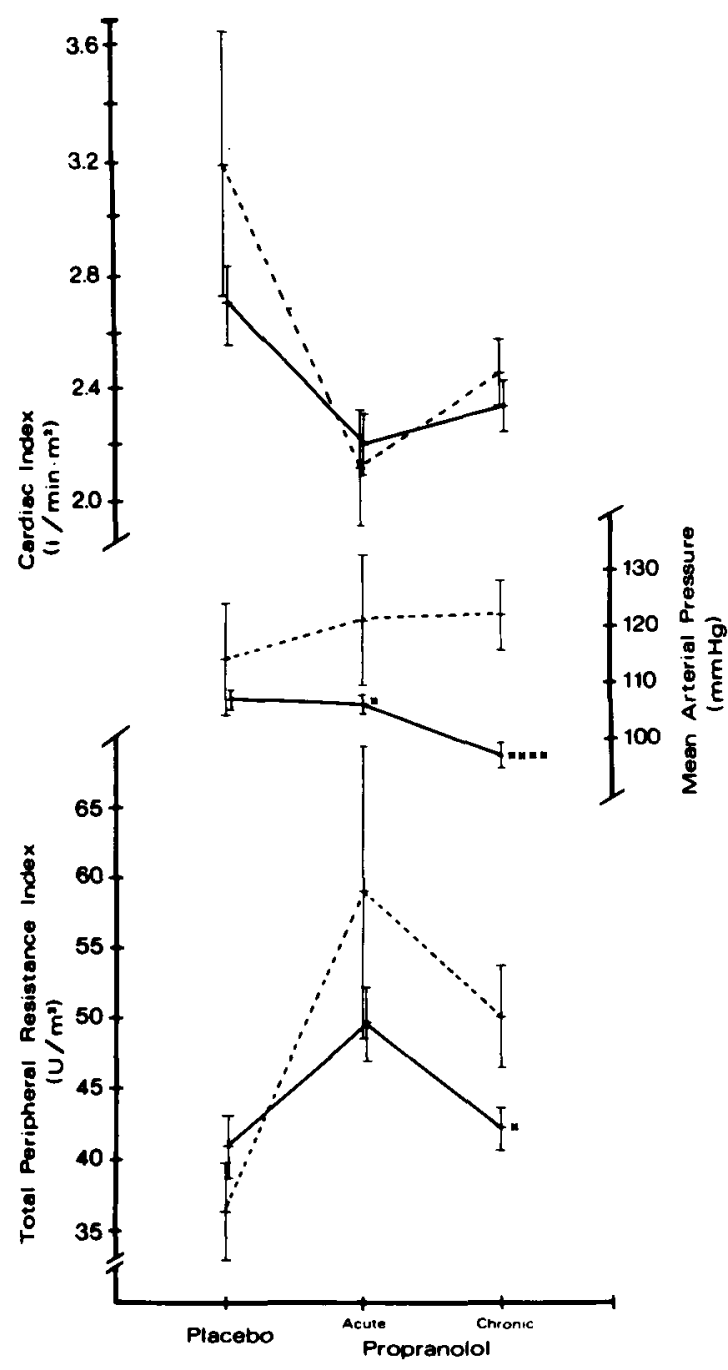

Fig. 3. Effect of acute i.v. and chronic oral adminstration of propranolol (mean \pm S.E.M.). Statistical comparison is between responders (-) and non-responders (- -) (Student's $t$-test). Probabilities as in Fig. 1. i.v. propranolol and after 4 weeks of oral therapy are presented in Table III. The effect on PRA of chronic propranolol therapy was striking, causing a reduction of stimulated (tilted) PRA by $85 \%$ (from 249 to $39 \mathrm{ng} / 100 \mathrm{ml} / \mathrm{h}, p<0.005$ ). However, the reduction of PRA was not significantly correlated to the change of MAP, TPRi or Qi either in the recumbent or tilted position (correlation coefficients $0.077-0.104, p<0.25$ ). Neither was the change of PRA, expressed in percent, significantly correlated to the percentage change of MAP, TPRi or Qi either recumbent or tilted (correlation coefficients $0.000-0.387, p>0.10$ ). There was no difference between responders and nonresponders in the reduction of PRA, the three nonresponders showing reductions of 81,90 and $96 \%$, respectively, as compared to $85 \%$ for the entire group.

\section{Effect on baroreceptor reflex}

Only in 7 patients was a statistically significant correlation between systolic BP and R-R interval (BP/R-R slope) obtained after angiotensin injection both in the untreated state and after four weeks of oral propranolol. The average $B P / R-R$ slope in the untreated state was 4.84 and after oral propranolol 7.64. The difference, $2.80 \pm 1.06$, did not quite achieve statistical significance $(p=0.115)$ (paired $t$-test).

\section{Effect of isoproterenol}

As described before, infusion of isoproterenol was used to assess the degree of $\beta$-adrenergic blockade in all patients. In the initial untreated state the HR increased by 39.4 beats/min $(p<0.0001)$ in response to the i.v. infusion of $3 \mu \mathrm{g} / \mathrm{min}$. There was no difference between responders (39.8) and non-responders $(38.0)$ in this respect. After acute

Table II. Hemodynamic changes during tilt

\begin{tabular}{|c|c|c|c|c|c|c|c|c|c|c|c|c|}
\hline & \multicolumn{4}{|c|}{ Placebo $(n=15)$} & \multicolumn{4}{|c|}{ I.v. propranolol ${ }^{a}(n=12)$} & \multicolumn{4}{|c|}{ Oral propranolol $^{b}(n=12)$} \\
\hline & Rest & Tilt & $\begin{array}{l}\text { Differ- } \\
\text { ence }\end{array}$ & $p<$ & Rest & Tilt & $\begin{array}{l}\text { Differ- } \\
\text { ence }\end{array}$ & $p<$ & Rest & Tilt & $\begin{array}{l}\text { Differ- } \\
\text { ence }\end{array}$ & $p<$ \\
\hline $\mathrm{Qi}\left(\mathrm{l} / \mathrm{min} \cdot \mathrm{m}^{2}\right)$ & 2.76 & 2.19 & 0.57 & 0.005 & 2.19 & 1.60 & 0.59 & 0.0005 & 2.44 & 2.04 & 0.40 & 0.005 \\
\hline $\mathrm{MAP}(\mathrm{mmHg})$ & 108.3 & 119.6 & 11.3 & 0.0005 & 106.4 & 98.3 & 8.1 & n.s. & 103.4 & 110.3 & 6.9 & 0.005 \\
\hline TPRi $\left(\mathrm{U} / \mathrm{m}^{2}\right)$ & 41.3 & 56.5 & 15.2 & 0.0001 & 50.4 & 63.8 & 13.4 & 0.005 & 42.6 & 54.6 & 10.0 & 0.0005 \\
\hline HR (beats $/ \mathrm{min}$ ) & 76.0 & 84.9 & 8.9 & 0.005 & 69.5 & 69.8 & 0.3 & n.s. & 57.7 & 60.6 & 2.9 & 0.01 \\
\hline $\mathrm{SVi}\left(\mathrm{ml} / \mathrm{m}^{2}\right)$ & 37.3 & 26.4 & 10.9 & 0.0001 & 32.0 & 22.9 & 9.1 & 0.0001 & 42.7 & 34.4 & 8.3 & 0.0005 \\
\hline
\end{tabular}

a $0.22 \mathrm{mg} / \mathrm{kg}$. o For 4 weeks, $160-320 \mathrm{mg} / \mathrm{d}$. (a verage $250 \mathrm{mg}$ ). 
Table III. PRA before and after $\beta$-adrenergic blockade

PRA (ng/ $100 \mathrm{ml} / \mathrm{h}$ ) tilt

\begin{tabular}{|c|c|c|}
\hline Placebo & $\begin{array}{l}\text { l.v. propranolol } \\
(0.22 \mathrm{mg} / \mathrm{kg})\end{array}$ & $\begin{array}{l}\text { Oral propranolol } \\
\text { (160-320 mg/d.) }\end{array}$ \\
\hline$\stackrel{248.7 \pm 69.8}{\longmapsto} p<0.01$ & $204.7 \pm 70.1$ & $39.0 \pm 10.1$ \\
\hline
\end{tabular}

i.v. administration of propranolol and repeated isoproterenol infusion at the rate of $3 \mu \mathrm{g} / \mathrm{min}$ the HR did not increase significantly ( 1.0 beats $/ \mathrm{min})$. Finally, following four weeks of oral propranolol the response to isoproterenol infusion was 5.3 beats/min (the increase in responders being 6.1 and in non-responders 2.0 beats/min), indicating that all patients had a significant degree of $\beta$ adrenergic blockade.

\section{Plasma propranolol determinations}

Average plasma propranolol concentration after acute i.v. administration of $0.22 \mathrm{mg}$ propranolol/ $\mathrm{kg}$ was $100.5 \pm 6.0 \mathrm{ng} / \mathrm{ml}$ and individual variations were small. Following four weeks of oral propranolol treatment, at either 160 or $320 \mathrm{mg}$ daily, the average plasma propranolol concentration was $123.1 \pm 46.1 \mathrm{ng} / \mathrm{ml}$. More than ten-fold variations between individual patients were observed. Correlations between the various hemodynamic and PRA changes and plasma propranolol concentrations were not statistically significant either after acute i.v. or after prolonged oral administration of propranolol. Nor was the response to isoproterenol infusion significantly correlated to plasma propranolol concentration.

\section{DISCUSSION}

The effect of propranolol was studied in 15 men with mild to moderately severe essential hypertension. In agreement with previously published results $(6,8,14,15,20,23)$ a $\mathrm{BP}$ reduction was seen in most cases following oral treatment.

Hemodynamically it was obvious that the i.v. administration of even $0.05 \mathrm{mg}$ propranolol $/ \mathrm{kg}$ caused a significant reduction of $H R$ and $Q$, while the decrease of SVi did not achieve statistical significance (Figs. 1 and 2). Doubling and quadrupling the dose further decreased $H R$ and $Q$, but the importance of these increments of dosage was minor.
Just as important was the finding that BP was not affected by this acute decrease of $Q$. Consequently, the calculated TPR had increased to a degree corresponding to the decrement of $\mathrm{Q}$. Obviously this is the effect which from a theoretical point of view should be expected from a $\beta$ adrenergic blocking agent.

After four weeks of oral administration of propranolol the $Q$ and $H R$ were still decreased. In contrast to the acute situation, however, the majority of patients now showed reduced BP with an accompanying reduction of TPR. This finding is in agreement with recent observations of others (20).

It is tempting to speculate about the underlying mechanisms explaining this phenomenon, particularly the question of why a chronic reduction of $Q$ would cause a readjustment of TPR in most patients. Resetting of baroreceptors has been suggested (15) and our data suggest a change of baroreceptors to a more sensitive setting. For a given increase of systolic BP a comparatively greater reduction of $\mathrm{HR}$ occurred after treatment. However, it should be stressed that we could not demonstrate a significant change of baroreceptor sensitivity, possibly due to the small number of patients available for this comparison. Furthermore it should be pointed out that a comparison to baroreceptor sensitivity was not made after acute $\beta$-adrenergic blockade. However, studies of the baroreceptor sensitivity, using the same technique as in the present study, although revealing some gain of reflex sensitivity after i.v. propranolol, showed that atropinization completely abolished the HR response to BP elevation (19). This would indicate that vagal effects are mainly responsible for the barorecptor-mediated reduction of HR and consequently it would be justified to compare the sensitivity in the untreated state to that after prolonged oral $\beta$-adrenergic blockade. Preliminary unpublished data of our own reveal that acute i.v. administration of propranolol, $0.22 \mathrm{mg} / \mathrm{kg}$, does not significantly alter the BP/ $\mathrm{R}-\mathrm{R}$ slope.

Our tilt results do not support the opinion by Oparil et al. (13) that renin plays an important role in the hemodynamic adjustments associated with postural changes. The vascular response to tilt after prolonged $\beta$-adrenergic blockade was not impaired in spite of marked reduction of PRA. It would therefore seem that renin/angiotensin is not 
directly responsible for the hemodynamic alterations during the acute change of posture.

The hypothesis that the hypotensive effect of propranolol is secondary to its local anesthetic effect and that in fact the reduction of BP would follow from anesthesia of vasoconstrictor fibers (4) is most interesting. However, it is hard to explain the different response to acute and chronic therapy using this explanation. Furthermore studies in man, using the dextroisomer of propranolol, which has no $\beta$-adrenergic blocking effect but retains the local anesthetic effect, have shown no hypotensive effect (22). Tarazi and Dustan (20) were the first to publish results indicating that reduction of BP during propranolol treatment follows from a long-term adaptation of peripheral resistance. Obviously our results are in full agreement with their statement, even if at present we are not able to explain the mechanism underlying this adjustment.

The marked reductions of stimulated PRA, and therefore logically also of angiotensin II, could theoretically reduce peripheral vascular resistance. However, the renin/angiotensin mechanism is not considered to be of etiological importance in mild essential hypertension, and PRA is usually normal or even low in this condition $(3,10)$. Our results are in agreement with such a view, as no significant correlation was seen between the change of PRA and the changes of MAP, Qi and, most importantly, TPRi. Furthermore, the reduction of PRA was equally pronounced in the three patients who showed no decrease of MAP. This indicates that reduction of PRA is not the major determinant of the antihypertensive mechanism of propranolol in mild essential hypertension. The lack of correlation between the change of PRA and the change of TPRi indicates that the readjustment of peripheral vascular resistance that takes place during prolonged treatment with propranolol is independent of the change of PRA.

Plasma propranolol concentration was not found to be correlated to either the hemodynamic changes or the effects of i.v. infusion of isoproterenol, which is in agreement with recent observations by others (24). This could indicate that tissue binding of propranolol is of greater importance than the plasma concentration. Other possibilities are that active metabolites, e.g. 4hydroxypropranolol, contribute significantly to the degree of $\beta$-adrenergic blockade.
Finally, the response to isoproterenol infusion failed to single out non-responders. However, we do not wish to draw any conclusions from this, as individual dose-response curves before and after propranolol were not made.

\section{CONCLUSIONS}

1. Acute $\beta$-adrenergic blockade does not cause reduction of $\mathrm{BP}$ in patients with essential hypertension. The reduction of $Q$ in this situation is compensated by a corresponding increase of TPR, thereby maintaining BP unaltered.

2. After four weeks of $\beta$-adrenergic blockade the Qi is still reduced but, due to an adjustment of TPR, the BP is significantly reduced in most patients.

3. The alterations of TPR and BP are not directly dependent on the marked reductions of stimulated PRA.

4. An increase of the $B P / R-R$ slope, although not statistically significant, indicated that baroreceptors may have been reset towards a greater sensitivity, thereby suggesting the mechanism whereby peripheral resistance is adjusted.

\section{ACKNOWLEDGEMENTS}

This work was supported by Michigan Heart Association, Ayerst Laboratories (Dr R. G. Mazlen, M.D.), USPHS grants 5-MO1-RR-42 and 2-P11-GM-15559. Dr Hansson was the recipient of a travel grant from the Swedish Medical Research Council and of a grant from the Swedish National Association against Heart and Chest Diseases.

\section{REFERENCES}

1. Bristow, J. D., Honour, A. J., Pickering, T. D. \& Sleight, P.: Cardiovascular and respiratory changes during sleep in normal and hypertensive subjects. Cardiovasc. Res. 3: 476, 1969.

2. Bühler, F. R., Laragh, J. H., Baer, L., Vaughan, E. D., Jr \& Brunner, H. R.: Propranolol inhibition of renin secretion. New Engl. J. Med. 287: 1209, 1972.

3. Crane, M. G., Harris, J. J. \& Johns, V. J., Jr: Hyporeninemic hypertension. Amer. J. Med. 52; 457, 1972.

4. Eliash, S. \& Weinstock, M.: Role of adrenergic neurone blockade in the hypotensive action of propranolol. Brit. J. Pharmacol. 43: 287, 1971.

5. Freis, E. D.: Hemodynamics in hypertension. Physiol. Rev. 40: 27, 1960.

6. Frohlich, E. D., Tarazi, R. C., Dustan, H. P. \& Page, I. H.: The paradox of $\beta$-adrenergic blockade in hypertension. Circulation 37: 417, 1968. 
7. Haber, E., Koerner, T., Page, L. B., Kliman, B. \& Purnode, A.: Application of a radioimmunoassay for angiotensin $I$ to the physiologic measurements of plasma renin activity in normal human subjects. J. clin. Endocr. 29: 1349, 1969.

8. Hansson, L., Malmcrona, R., Olander, R., Rosenhall, L., Westerlund, A., Åberg, H. \& Hood, B.: Propranolol in hypertension. Report on 158 patients treated up to one year. Klin. Wschr. 50: 364, 1972.

9. Hansson, L. \& Zweifler, A. J.: The effect of propranolol on plasma renin activity and blood pressure in mild essential hypertension. Acta med. scand. 195: 397, 1974.

10. Jose, A., Crout, J. R. \& Kaplan, N. M.: Suppressed plasma renin activity in essential hypertension. Roles of plasma volume, blood pressure and sympathetic nerve system. Ann. intern. Med. 72: $9,1970$.

11. Lund-Johansen, P.: Hemodynamics in early essential hypertension. Acta med. scand., Suppl. 482, 1967.

12. Moore, J. W., Kinsman, J. M., Hamilton, W. F. \& Spurling, R. G.: Studies on the circulation: II. Cardiac output determination. Amer. J. Physiol. 89: $331,1929$.

13. Oparil, S., Vassaux, D., Sanders, C. A. \& Haber, E.: Role of renin in acute postural homeostasis. Circulation 41: 89, 1970.

14. Prichard, B. N. P. \& Gillam, P. M. S.: Use of propranolol (Inderal) in treatment of hypertension. Brit, med. J. 2: 725, 1964.

15. - Treatment of hypertension with propranolol. Brit. med. J. 1: 71969.

16. Prichard, B. N. P., Shinebourne, E., Fleming, J. \&
Hamer, $\mathrm{J}$.: Hemodynamic studies in hypertensive patients on oral propranolol. Brit. Heart. J. 32: 236, 1970.

17. Sannerstedt, R.: Hemodynamic response to exercise in patients with arterial hypertension. Acta med. scand., Suppl. 458, 1966.

18. Shand, D. G., Nucholls, E. M. \& Oates, J. A.: Plasma propranolol levels in adults. With observations in four children. Clin. Pharmacol. Ther. 11: 112, 1970.

19. Sleight, P., Gribbin, B. \& Pickering, T. G.: Baroreflex sensitivity in normal and hypertensive man: The effect of $\beta$-adrenergic blockade on reflex sensitivity. Postgrad. med. J., Suppl. 47: 79, 1971.

20. Tarazi, R. C. \& Dustan, H. P.: $\beta$-adrenergic blockade in hypertension. Practical and theroetical implications of long-term hemodynamic variations. Amer. J. Cardiol. 29: 633, 1972.

21. Ulrych, M., Frohlich, E. D. \& Dustan, H. P.: Immediate effects of $\beta$-adrenergic blockade with propranolol in normotensive and hypertensive man. Circulation 37: 411, 1968.

22. Waal-Manning, H. J.: Lack of effect of d-propranolol on blood pressure and pulse rate in hypertensive patients. Proc. Univ. Otago med. Sch. 48: 80, 1970.

23. Zacharias, F. J., Cowen, K. J., Prestt, J., Vickers, J. \& Wall, B. G.: Propranolol in hypertension: A study of long-term therapy 1964-1970. Amer. Heart J. 83: 755, 1972.

24. Zachest, R. \& Koch-Weser, J.: Relation of propranolol plasma level to blockade during oral therapy. Pharmacology 7: 178, 1972. 